\title{
The Miniature Pig as an Animal Model for the Study of Intestinal Enzyme Development
}

\author{
R. J. SHULMAN, S. J. HENNING, AND B. L. NICHOLS \\ USDA/ARS Children's Nutrition Research Center, Department of Pediatrics, Baylor College of Medicine and \\ Texas Children's Hospital, Houston, Texas 77030 and Department of Biology, University of Houston, \\ Houston, Texas 77004
}

\begin{abstract}
Studies of intestinal enzyme development and regulation relevant to the human infant require an animal model with a rate of maturation similar to that of the human infant. Hanford miniature pigs were weaned at 3 days of age to a standard swine weaning formula. At 1 , $2,3,4,5$, and 6 wk of age, duodenal jejunal, and ileal segments were analyzed for protein content and lactase, sucrase, maltase, glucoamylase, and acid $\beta$-galactosidase activities. Protein content of the small intestine changed significantly with age only in the ileum $(p<0.05)$. Lactase activity fell significantly with age in all segments of the small intestine $(p<0.001)$; activity was highest in the jejunum. Sucrase and maltase activities were present in all segments of the small intestine at 1 wk of age. Sucrase increased significantly ( 2 -fold, $p<0.02$ ) with age only in the ileum and maltase increased significantly with age in the jejunum (by $50 \%, p<0.05)$ and the ileum (3-fold, $p<$ 0.001 ). Activities were highest in the jejunum. Glucoamylase activity was present at 1 wk of age and showed a small but significant increase with age only in the duodenum $(p$ $<0.005$ ). Acid $\beta$-galactosidase activity demonstrated small but significant decreases with age in all small intestinal segments. Glucoamylase and acid $\beta$-galactosidase activities were similar in all segments. In the 6-wk-old pigs, activities of all the enzymes tested were similar to those found in young human infants. Our data demonstrate that the small intestinal enzyme development of the infant miniature pig is more advanced postnatally than other more commonly used animal species. The degree of small intestinal maturation and the similar intestinal enzyme distribution compared with that of the human infant suggest that the infant miniature pig is an excellent model for studies of intestinal enzyme development and regulation. (Pediatr Res 23: 311315,1988 )
\end{abstract}

Abbreviation

PCMB, P-chloromercuribenzoate

Clinically relevant studies of the development and regulation of intestinal enzymes in the human infant have been hampered

Received March 23, 1987; accepted November 16, 1987.

Publication of the USDA/ARS Children's Nutrition Research Center, Baylor College of Medicine and Texas Children's Hospital, Houston, TX. This project has been funded in part with federal funds from the U.S. Department of Agriculture, Agricultural Research Service under Cooperative Agreement 58-7MNI-6-100. The contents of this publication do not necessarily reflect the views or policies of the U.S. Department of Agriculture, nor does mention of trade names, commercial products, or organizations imply endorsement by the U.S. Government.

Correspondence and reprint requests to Robert J. Shulman, M.D., Children's Nutrition Research Center, 6608 Fannin, Suite 601, Houston, TX 77030. by the lack of an animal model with a comparable rate of maturation. Previous laboratory investigations have made extensive use of the rat, mouse, and rabbit, animals in which the major developmental changes in digestive enzymes, such as disaccharidases, are found postnatally $(1-4)$. By contrast, sucrase and maltase activities in the human newborn are at levels comparable to those found at maturity (5). Thus, findings regarding the modulation of small intestinal enzymes in the animal species cited may have little relevance to the human.

The pig is a logical candidate for studies of intestinal enzyme development because of similarities to the human in relation to intestinal anatomy and nutritional requirements (6-8). Previous studies of pig intestinal enzyme activity indicate a level of intestinal maturity at birth which is intermediate to that of the species named above and the human $(9,10)$. Much variability has been noted, however, in the rate of maturation of intestinal enzymes in the pig (9-12). The variability probably is due to the wide variety of strains used $(11,12)$. In recent years, various breeds of miniature pigs have been developed specifically for scientific investigations. These small pigs offer ease of handling and decreased cost when compared with full-size animals. Intestinal enzyme development, however, has not been characterized previously in the miniature pig.

Herein we have ascertained that the maturation of intestinal enzymes in the newborn Hanford miniature piglet is substantially more advanced than that in infant rats, mice, and rabbits. Indeed, the intestinal enzyme activity of the piglet bears a striking resemblance to that found in the human newborn. These data suggest that the miniature piglet is an excellent animal model for studies of intestinal enzyme development and regulation.

\section{MATERIALS AND METHODS}

Animals. Hanford miniature pigs (Charles River Breeding Laboratories, Wilmington, MA) were weaned at 3 days of age to a standard swine weaning formula (Soweena, Merrick's, Union Center, WI). At 1 wk of age, the animals were switched from the liquid formula to the pellet form of the same diet as recommended by the manufacturer. The liquid and pellets are comparable in composition to sow milk in terms of protein, fat, and carbohydrate (lactose) content (13). The piglets were shipped to our facility 2 to 4 days before our study began. From two to four animals were housed in each cage and were allowed free access to water and feed. The temperature of the room was maintained at $26^{\circ} \mathrm{C}$ with a 12 -h light cycle $(0600$ to $1800 \mathrm{~h})$. Heating mats (Nasco, Ft. Atkinson, WI) were placed in the cages to maintain the local temperature between 32 to $35^{\circ} \mathrm{C}$. The animals were weighed daily to the nearest gram on an electric balance (Sartorius, Goettingen, Germany).

Tissue collection. At 1, 2, 3, 4, 5, and $6 \mathrm{wk}$ of age, the animals were anesthetized with $0.05 \mathrm{mg} / \mathrm{kg}$ of fentanyl and $11.0 \mathrm{mg} / \mathrm{kg}$ ketamine administered intramuscularly. The abdomen was 
opened and the entire small intestine was quickly removed and placed in ice-cold saline. The intestine from the pylorus to the peritoneal reflection (analogous to the ligament of Treitz) was defined as the duodenum. The remaining small intestine was divided equally into proximal (jejunum) and distal (ileum) portions. Because of the large length of intestine, the duodenum, jejunum, and ileum were further cut into three equal segments. The middle segment of each was used for analyses. The segments were rinsed thoroughly with ice-cold saline, opened length-wise, and blotted dry. The mucosa was removed by scraping with a glass slide and frozen in liquid nitrogen in preweighed containers. The containers were reweighed to the nearest $0.1 \mathrm{mg}$ and stored at $-20^{\circ} \mathrm{C}$.

Analyses. After homogenization in deionized water, the mucosa was assayed for lactase, sucrase, and maltase activities as previously described $(14,15)$. In brief, after the homogenate was incubated at $37^{\circ} \mathrm{C}$ with the appropriate substrate, the liberated glucose was measured using a glucose oxidase reagent (Worthington Statzyme 500, Cooper Biomedical, Freehold, NJ). PCMB was used in the lactase assay; preliminary studies had shown that in the absence of PCMB, lysosomal hydrolysis accounts for approximately $12 \%$ of lactase hydrolysis (16). Glucoamylase activity was measured by the method of Eggermont (17) as modified by Galand and Forstner (18). Acid $\beta$-galactosidase activity was measured using the technique described by Koldovsky and Sunshine (19). Protein content was determined using the method of Lowry et al. (20).

Statistics. Changes in enzyme activity with age were assessed using regression analysis. Differences in enzyme activity between intestinal segments were determined by a repeated measures analysis of variance using animal and gut segments as factors to compare the mean enzyme activities of the three segments. A multiple comparison procedure (Bonferroni) was then used to make pair-wise comparisons between intestinal segments. Enzyme activity was expressed per g of protein (i.e. specific activity) except where noted.

\section{RESULTS}

The amount of small intestinal mucosa in the duodenum, jejunum, and ileum increased proportionally with the weight (Table 1; duodenum, jejunum, and ileum: $p<0.001$ ) and age (Table 1; duodenum, jejunum, and ileum: $p<0.001$ ) of the piglets. The increase in mucosal weight was proportionally

Table 1. Wt of piglets and wet weight of mucosa from duodenum, jejunum, and ileum (mean $\pm S E)$

\begin{tabular}{ccccrr}
\hline $\begin{array}{c}\text { Age } \\
(\text { wk) }\end{array}$ & $n$ & Piglets $(\mathrm{g})$ & $\begin{array}{c}\text { Duodenum } \\
(\mathrm{g})\end{array}$ & \multicolumn{1}{c}{$\begin{array}{c}\text { Jejunum } \\
(\mathrm{g})\end{array}$} & \multicolumn{1}{c}{ Ileum $(\mathrm{g})$} \\
\hline 1 & 7 & $1398 \pm 89$ & $0.4 \pm 0.0$ & $5.5 \pm 0.6$ & $6.8 \pm 1.0$ \\
2 & 7 & $2064 \pm 155$ & $0.7 \pm 0.1$ & $9.1 \pm 0.5$ & $12.5 \pm 1.4$ \\
3 & 7 & $2420 \pm 180$ & $0.9 \pm 0.1$ & $14.7 \pm 1.3$ & $11.9 \pm 1.6$ \\
4 & 4 & $3386 \pm 286$ & $1.7 \pm 0.3$ & $27.3 \pm 3.0$ & $20.6 \pm 2.9$ \\
5 & 7 & $5111 \pm 161$ & $2.2 \pm 0.1$ & $35.1 \pm 2.0$ & $30.4 \pm 3.1$ \\
6 & 7 & $7279 \pm 413$ & $3.0 \pm 0.4$ & $46.7 \pm 3.6$ & $40.4 \pm 2.7$ \\
\hline
\end{tabular}

Table 2. Protein content of mucosa from duodenum, jejunum, and ileum (mean $\pm S E$ )

\begin{tabular}{ccccc}
\hline $\begin{array}{c}\text { Age } \\
\text { (wk) }\end{array}$ & $n$ & $\begin{array}{c}\text { Duodenum } \\
(\mathrm{mg} / \mathrm{g} \text { wet wt) }\end{array}$ & $\begin{array}{c}\text { Jejunum } \\
(\mathrm{mg} / \mathrm{g} \text { wet wt })\end{array}$ & $\begin{array}{c}\text { Ileum } \\
(\mathrm{mg} / \mathrm{g} \text { wet wt })\end{array}$ \\
\hline 1 & 7 & $104.7 \pm 4.1$ & $108.1 \pm 5.1$ & $96.1 \pm 6.5$ \\
2 & 7 & $103.7 \pm 7.0$ & $118.3 \pm 4.2$ & $106.6 \pm 3.3$ \\
3 & 7 & $83.7 \pm 3.0$ & $106.0 \pm 3.8$ & $103.8 \pm 4.2$ \\
4 & 4 & $105.7 \pm 1.9$ & $115.4 \pm 1.3$ & $107.0 \pm 2.6$ \\
5 & 7 & $108.0 \pm 3.6$ & $110.1 \pm 3.1$ & $106.1 \pm 2.6$ \\
6 & 7 & $105.6 \pm 3.6$ & $118.7 \pm 2.6$ & $110.4 \pm 4.9$ \\
\hline
\end{tabular}

greater than the increase in body weight. The amount of protein per wet weight in the duodenal and jejunal mucosa did not change significantly between 1 and 6 weeks of age (Table 2). A significant $(p<0.05)$ increase with age was found in the ileal protein content (Table 2 ).

Lactase specific activity (Fig. 1) declined significantly with age in all regions of the small intestine (duodenum, jejunum, and ileum: $p<0.001$ ). Lactase activity was highest in the jejunum (versus duodenum, $p<0.001$; versus ileum, $p<0.001$ ).

Sucrase activity (Fig. 2) was present at 1 wk of age in all regions of the small intestine and showed an approximate 2 -fold increase in activity in the ileum by 6 wk of age $(p<0.02)$. Activity in the duodenum and jejunum did not change significantly with age. Activity was highest in the jejunum (versus duodenum, $p<$ 0.001 ; versus ileum, $p<0.001$ ).

Maltase activity (Fig. 3) was also present at $1 \mathrm{wk}$ of age; enzyme activity showed a small but significant increase with age in the jejunum and ileum ( $p<0.05$ and $p<0.001$, respectively). Activity was highest in the jejunum (versus duodenum, $p<$

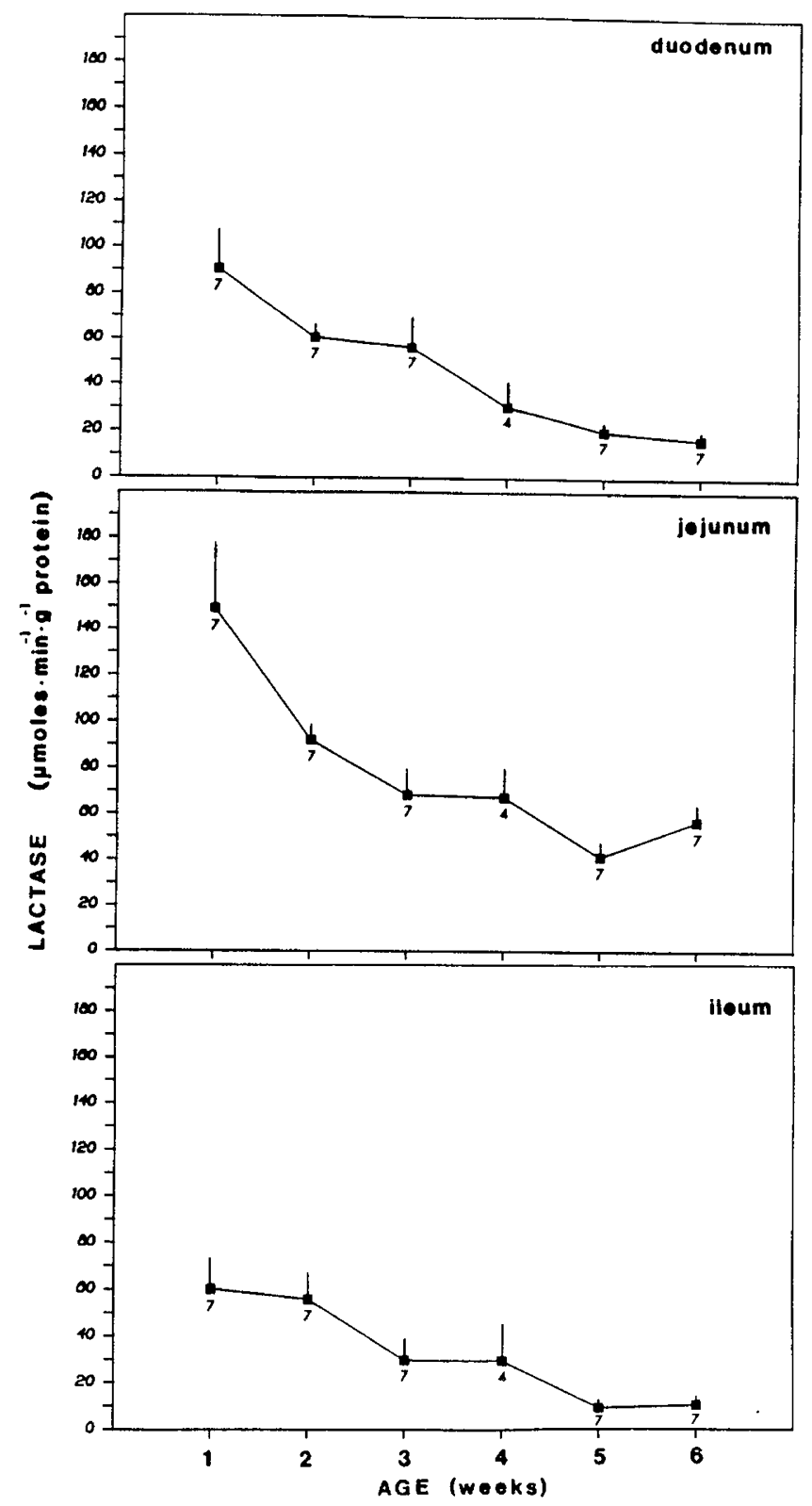

Fig. 1. Specific activity of lactase in the mucosa from the duodenum, jejunum, and ileum (mean \pm SEM). Sample size is indicated below each symbol. 
0.001 ; versus ileum, $p<0.001$ ), but showed less variability in activity along the gastrointestinal tract than lactase and sucrase.

Glucoamylase activity (Fig. 4) showed no significant change with age; activity was similar among the segments of duodenum, jejunum, and ileum. Acid $\beta$-galactosidase activity (Fig. 5) demonstrated a small but significant decrease with age in all regions of the small intestine (duodenum: $p<0.02$, jejunum: $p<0.02$; ileum: $p<0.05$ ). Activity was similar among the segments.

\section{DISCUSSION}

Although our study demonstrated postnatal alterations in disaccharidase activity in the miniature pig, the magnitude of the changes was much less than that found in other laboratory fold during the first $4 \mathrm{wk}$ of life in contrast to the miniature pig which demonstrated a 2 -fold decrease (2). The rat, mouse, and rabbit show little or no sucrase activity at $1 \mathrm{wk}$ of age (1-4). They have barely detectable sucrase activity at $2 \mathrm{wk}$ of age, whereas by $6 \mathrm{wk}$, the activity has increased 25 - to 100 -fold (3, 4). In comparison, the miniature pigs demonstrated sucrase
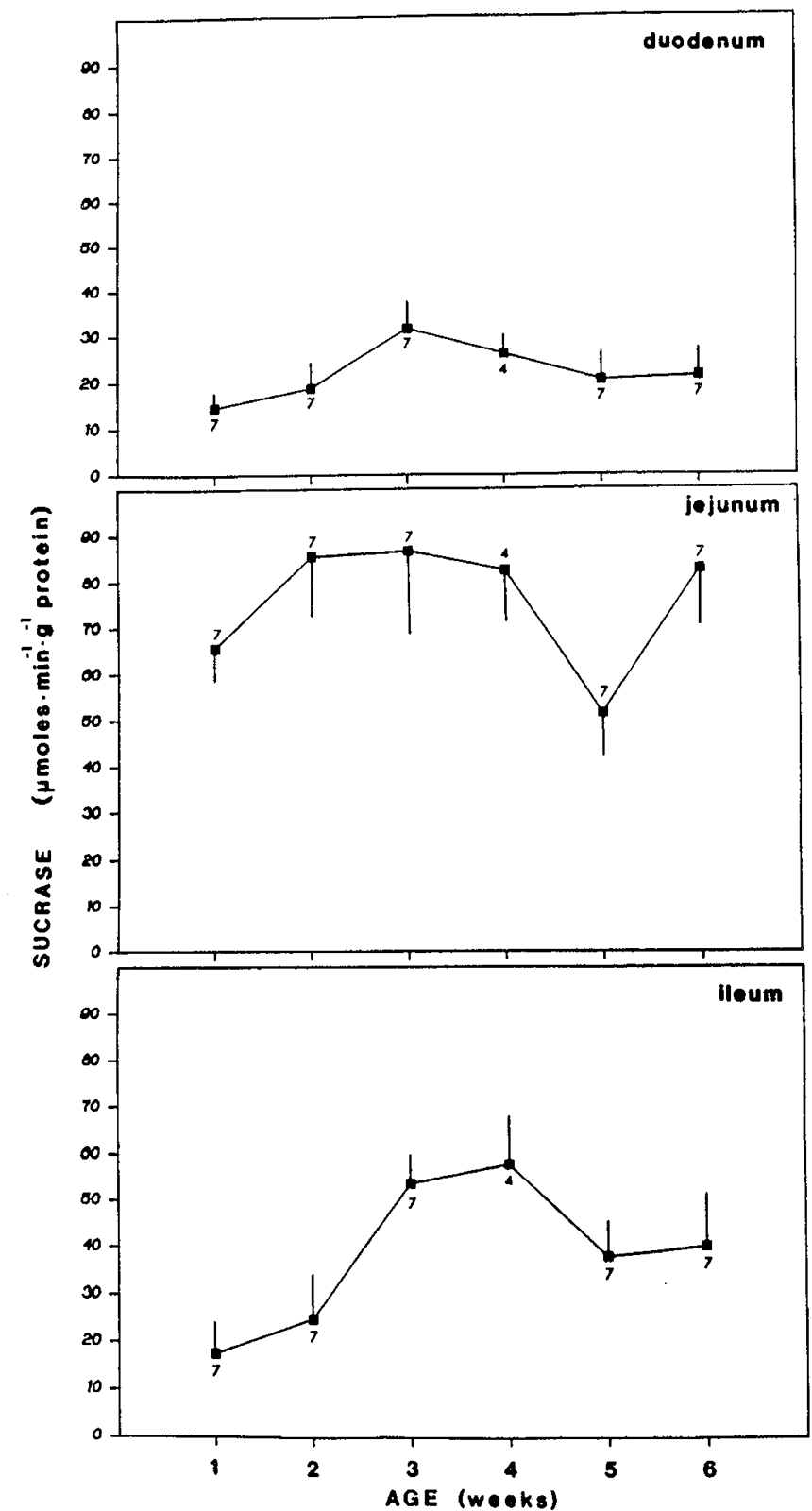

Fig. 2. Specific activity of sucrase in the mucosa from the duodenum, jejunum, and ileum (mean \pm SEM). Sample size is indicated below each symbol. activity at $1 \mathrm{wk}$ of age which was generally more than half that found at $6 \mathrm{wk}$. Maltase activity followed a similar pattern. Postnatal changes in sucrase and maltase activities in the human are not significant (5). Our results demonstrate that the small intestine of the miniature pig, compared with that of the rat, mouse, or rabbit, achieves a level of maturation after birth that is much more comparable to that of the human.

In the human, glucoamylase and acid $\beta$-galactosidase activities do not change after birth $(21,22)$. To our knowledge, data are not available about developmental changes in glucoamylase activity in the rat, mouse, or rabbit. Acid $\beta$-galactosidase activity in the rat, however, shows a sharp decline postnatally (19). The similar postnatal increase in the activities of sucrase, maltase, and to a degree, glucoamylase found in the miniature pig is not unexpected because these enzymes share some homology in their specificities for substrates (23).

The jejunal activities of the disaccharidases, glucoamylase, and acid $\beta$-galactosidase in the 6 -wk-old pigs were similar to those found in young human infants. The jejunal activities of lactase and sucrase were similar to those found in adults (i.e. lactase-

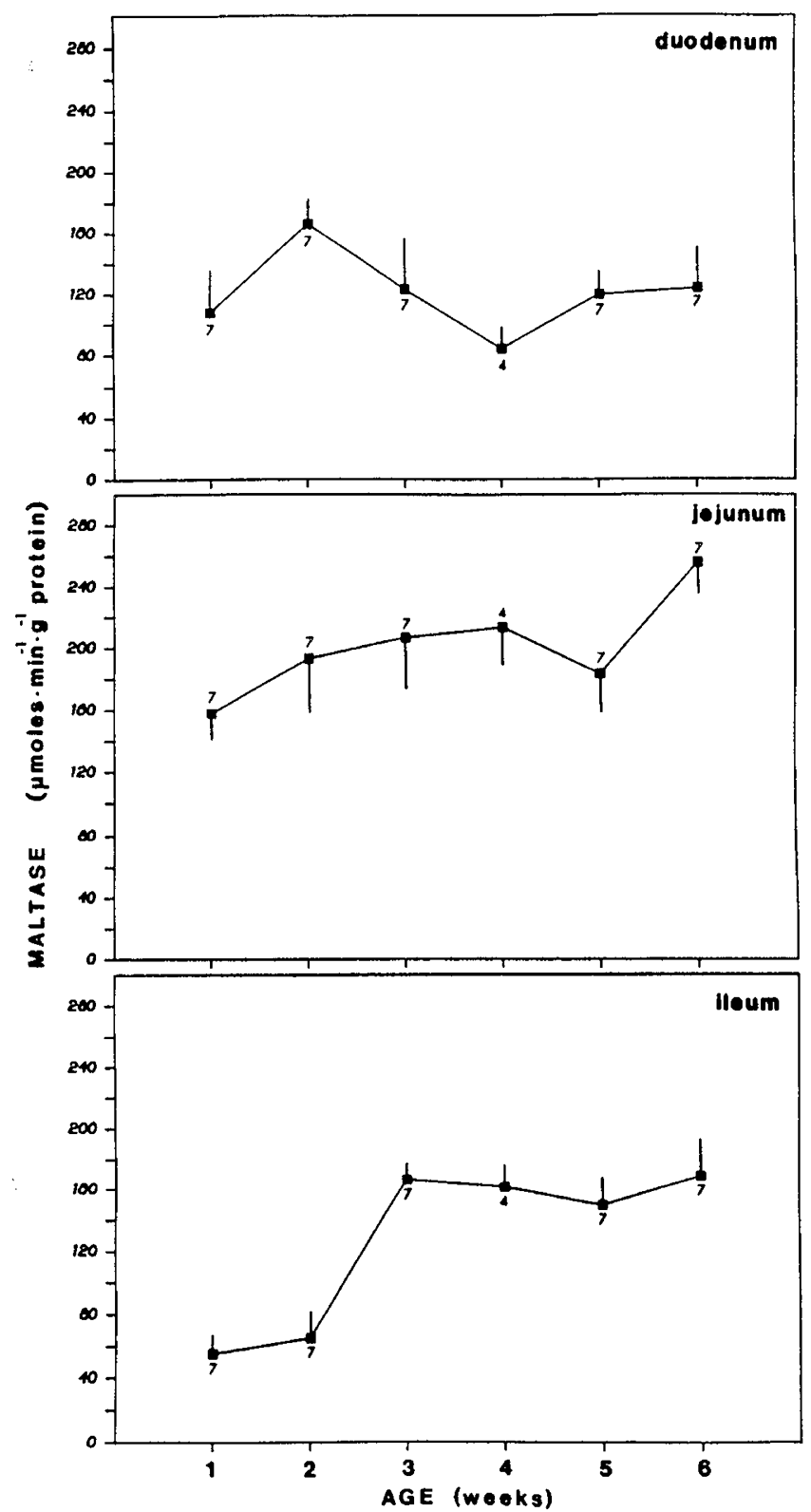

Fig. 3. Specific activity of maltase in the mucosa from the duodenum, jejunum, and ileum (mean \pm SEM). Sample size is indicated below each symbol. 


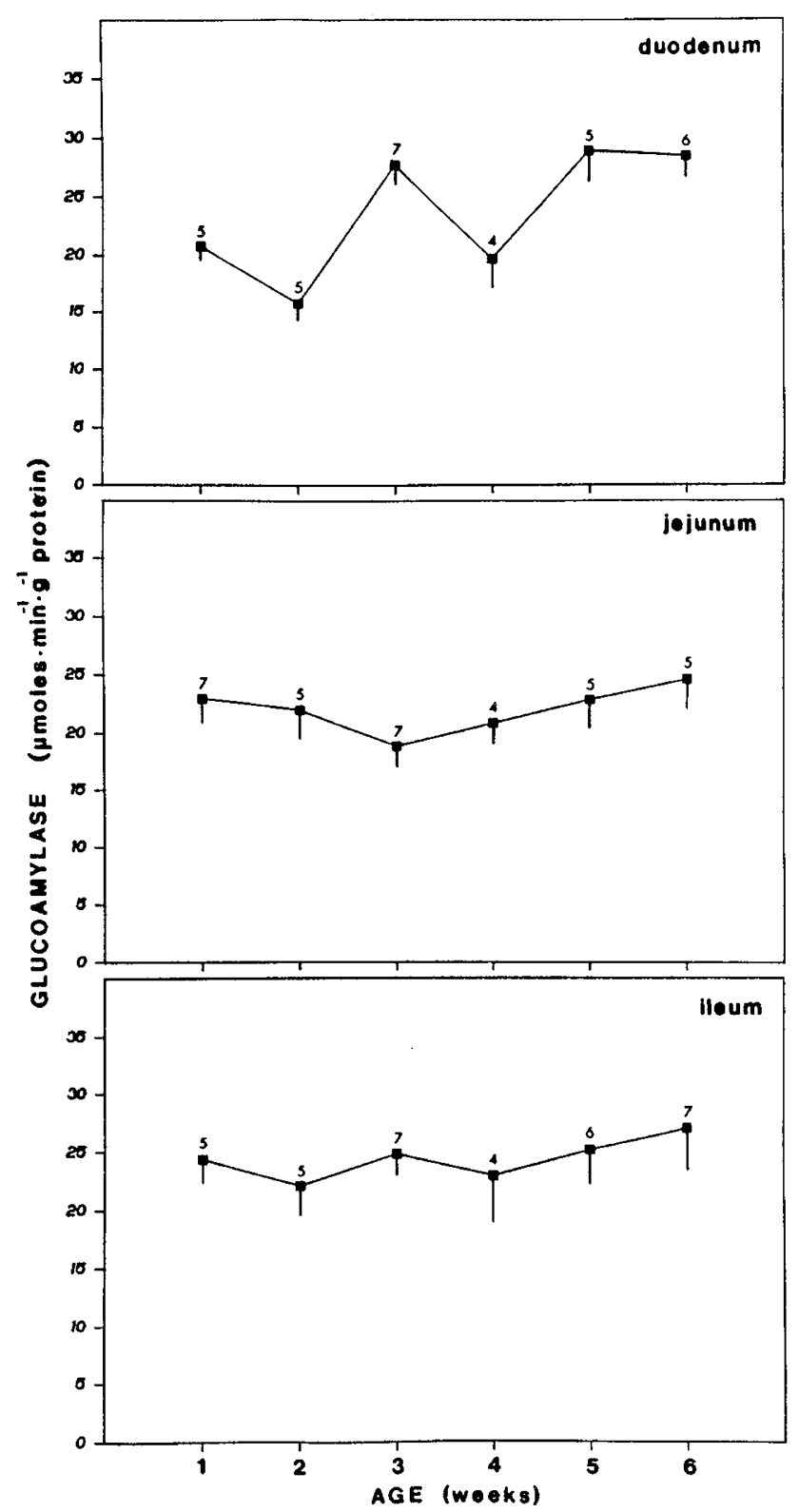

Fig. 4. Glucoamylase activity in the mucosa from the duodenum, jejunum, and ileum (mean \pm SEM). Sample size is indicated below each symbol.

sufficient) $(21,22,24)$. In contrast, jejunal disaccharidase activities in the mouse between 4 and 5 wk of age, and jejunal acid $\beta$-galactosidase activity in the rat between 8 and 9 wk of age are generally lower than those in young human infants $(2,19,21)$.

The distribution of the enzyme activities along the gastrointestinal tract of the pig was similar to that found in infant and adult humans $(5,25,26)$. Lactase activity was highest in the jejunum and lowest in the ileum, whereas sucrase activity was highest in the jejunum and lowest in the duodenum. Maltase activity was highest in the jejunum, but more evenly distributed along the small intestine than was that of lactase and sucrase. Glucoamylase activity was similar among the small intestinal segments. Acid $\beta$-galactosidase activity in the miniature pig, as in the human, tended to be higher in the upper small bowel in contrast to that of the rat, where the activity is greatest in the ileum (19, 21).

The activities and the developmental patterns of the disaccharidases in the miniature pig demonstrated some similarity to those found in some studies of full-size pigs. The fall in jejunal lactase activity found in our study was similar to that described

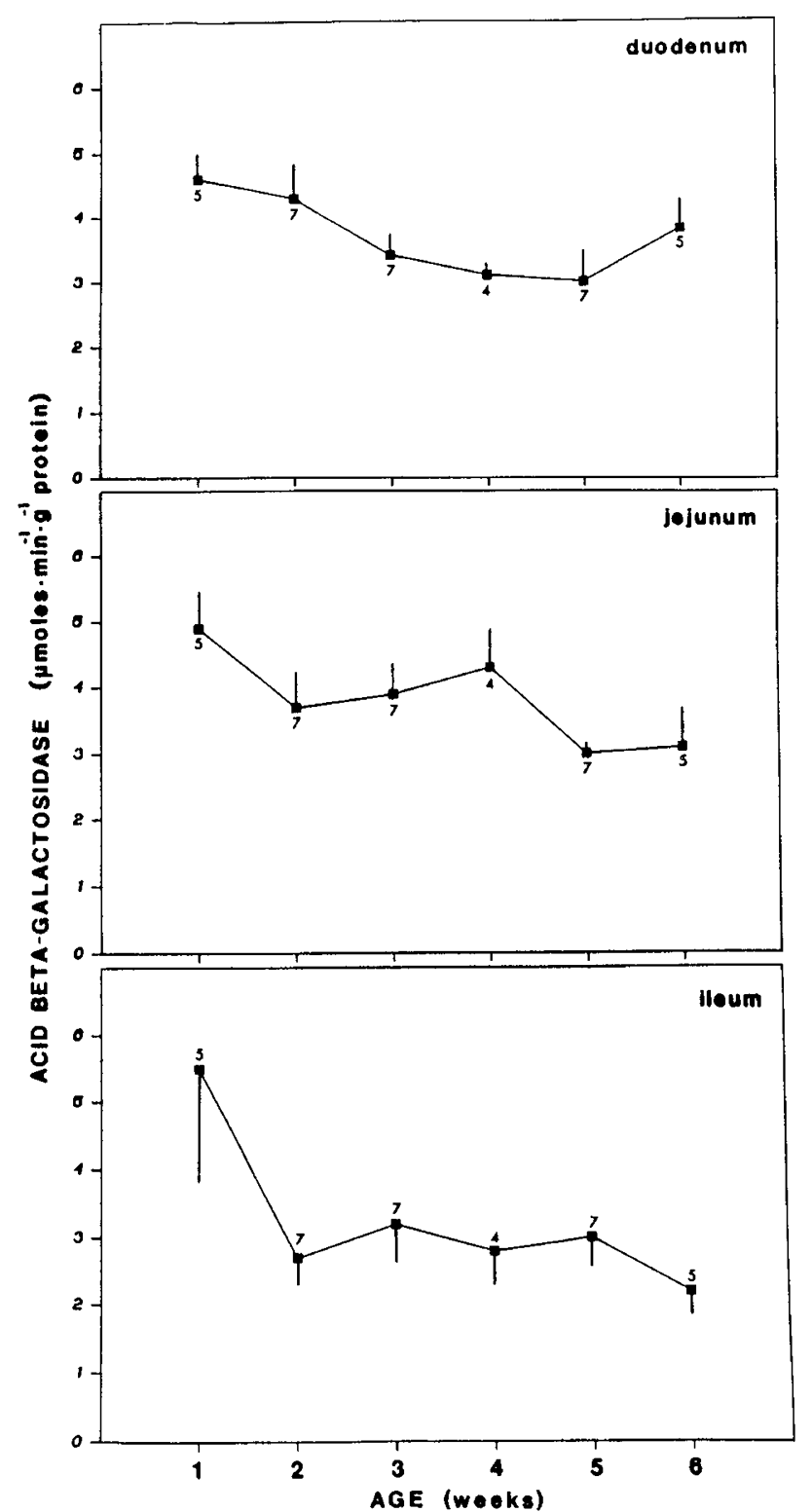

Fig. 5. Acid $\beta$-galactosidase activity in the mucosa from the duodenum, jejunum, and ileum (mean \pm SEM). Sample size is indicated below each symbol.

in full-size pigs (9-11). In contrast to our findings in miniature pigs, full-size pigs have been shown to have significant rises (2to 3 -fold) in jejunal sucrase activity after birth $(9,11)$. In a study by Aumatire and Corring (9), jejunal maltase activity in full-size pigs rose between birth and one week and then fell somewhat between 2 and 4 wk.

The ideal animal model for the study of small intestinal enzyme development should have the same developmental pattern as the human, be easy to manipulate technically, be inexpensive to maintain, and have large litters so that animals can be randomized to different treatment groups. Currently, no animal model meets all these criteria. The miniature pig, however, is sociable, easily trained, small, relatively inexpensive to house, and has a litter size of six to eight animals (6-8). Furthermore, the digestive physiology, gastrointestinal anatomy, and nutrient requirements of the pig are comparable to those of the human $(6-8,27)$. The larger size of the infant miniature pig compared with that of rats, mice, and rabbits also allows for both easier prenatal and postnatal studies of factors affecting small intestinal enzyme maturation and small intestinal growth. The miniature pig can be rapidly weaned after birth or can even be 
fed intravenously permitting the study of the effect of different diets on intestinal maturation and growth (28). We conclude, therefore, that the infant miniature pig is a more appropriate and practical model for the human infant than the rat, mouse, or rabbit, species commonly used in studies of intestinal digestive enzyme development.

Acknowledgments. The authors thank S. Perkinson, MT (ASCP) for expert technical assistance, E. O'Brian Smith, Ph.D. for assistance in the statistical analysis, Yolanda Garza and E. Roseland Klein for editorial assistance, and M. E. Lewis for manuscript preparation.

\section{REFERENCES}

1. Henning SJ 1981 Postnatal development: coordination of feeding, digestion, and metabolism. Am J Physiol 241:G199-214

2. Moog F, Denes AE, Powell PM 1973 Disaccharidases in the small intestine of the mouse: normal development and influence of cortisone, actinomycin D, and cycloheximide. Dev Biol 35:143-159

3. Lamers WH, Mooren PG, Charles R 1985 Perinatal development of the small intestine and pancreas in rat and spiny mouse. Biol Neonate 47:153-162

4. Toofanian F 1984 The fetal and postnatal development of small intestinal disaccharidases in the rabbit. Lab Anim Sci 34.268-271

5. Grand RJ, Watkins JB, Torti FM 1976 Development of the human gastrointestinal tract. Gastroenterology 70:790-810

6. Pond WG, Haupt KA 1978 The pig as a model in biomedical research. In: The Biology of the Pig. Cornell University Press, Ithaca, NY, pp 40-41

7. Schneider DL, Sarett HP 1966 Use of the hysterectomy-obtained SPF pig for nutritional studies of the neonate. J Nutr 89:143-164

8. Book SA, Bustad LK 1974 The fetal and neonatal pig in biomedical research. J Anim Sci 38:997-1002

9. Aumaitre A, Corring T 1978 Development of digestive enzymes in the piglet from birth to 8 weeks. Nutr Metab 22:244-255

10. Hartman PA, Hays VW, Baker RO, Neagle LH, Catron DV 1961 Digestive enzyme development in the pig. J Anim Sci 20:114-123

11. Manners MJ, Stevens JA 1972 Changes from birth to maturity in the pattern of distribution of lactase and sucrase activity in the mucosa of the small intestine of pigs. Br J Nutr 28:113-127
12. Engstrom MA, Ekstrom KE, Mahan DC 1979 Intestinal disaccharidase activities of three breeds of swine. J Anim Sci 48:1349-1356

13. Widdowson EM 1985 Development of the digestive system: comparative animal studies. Am J Clin Nutr 41:384-390

14. Henning SJ, Leeper LL 1982 Coordinate loss of glucocorticoid responsiveness by intestinal enzymes during postnatal development. Am J Physiol 242:G89G94

15. Martin GR, Henning SJ 1982 Relative importance of corticosterone and thyroxine in the postnatal development of sucrase and maltase in rat small intestine. Endocrinology 111:912-918

16. Koldovsky O, Asp NG, Dahlquist A 1969 A method for the separate assay of neutral and acid beta-galactosidase in homogenates of rat small-intestinal mucosa. Anal Biochem 27:409-418

17. Eggermont E 1969 The hydrolysis of the naturally occurring alpha-glucosides by the human intestinal mucosa. Eur J Biochem 9:483-487

18. Galand G, Forstner GG 1974 Soluble neutral and acid maltases in the suckling rat intestine. Biochem J 144:281-292

19. Koldovsky O, Sunshine P 1970 Effect of cortisone on the developmental pattern of the neutral and the acid beta-galactosidase of the small intestine of the rat. Biochem J 117:467-471

20. Lowry OH, Rosebrough NJ, Farr AL, Randall RJ 1951 Protein measurement with the folin phenol reagent. J Biol Chem 193:265-275

21. Antonowicz I, Chang SK, Grand RJ 1974 Development and distribution of lysosomal enzymes and disaccharidases in human fetal intestine. Gastroenterology 67:51-58

22. Lebenthal E, Lee PC 1980 Glucoamylase and disaccaridase activities in normal subjects and in patients with mucosal injury of the small intestine. J Pediatr 97:389-393

23. Gray GM 1975 Carbohydrate digestion and absorption. N Engl $\mathfrak{J}$ Med 292:1225-1230

24. Newcomer AD, McGill DB 1966 Distribution of disaccharidase activity in the small bowel of normal and lactase-deficient subjects. Gastroenterology 51:481-488

25. Raul F, Lacroix B, Aprahamian M 1986 Longitudinal distribution of brush border hydrolases and morphological maturation in the intestine of the preterm infant. Early Hum Dev 13:225-234

26. Triadou N, Bataille J, Schmitz J 1983 Longitudinal study of the human intestinal brush border membrane proteins. Gastroenterology 85:1326-1332

27. Glauser EM 1966 Advantages of piglets as experimental animals in pediatric research. Exp Med Surg 24:181-190

28. Shulman RJ, Fiorotto ML, Sheng H-P, Garza C 1984 Effect of different total parenteral nutrition fuel mixes on the body composition of infant miniature pigs. Pediatr Res 18:861-865 